Copyright by the American Institute of Physics (AIP). Abdelkefi, A.; Scanlon, J. M.; McDowell, E.; et al., "Performance enhancement of piezoelectric energy harvesters from wake galloping," Appl. Phys. Lett. 103, 033903 (2013); http:// dx.doi.org/10.1063/1.4816075

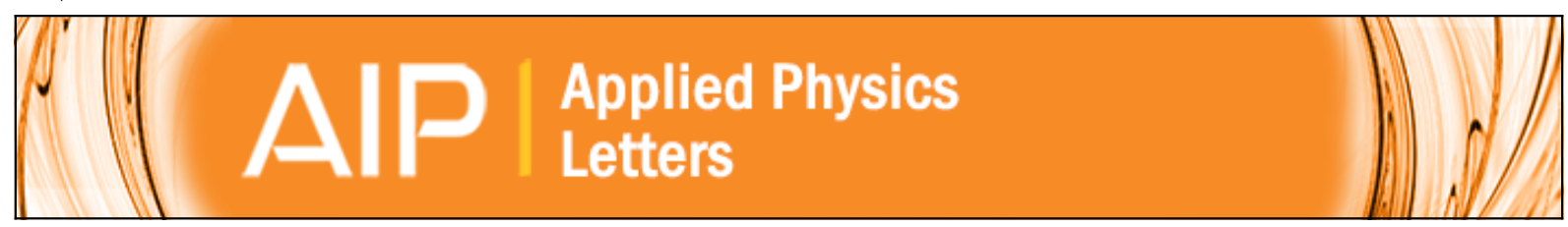

Performance enhancement of piezoelectric energy harvesters from wake galloping

A. Abdelkefi, J. M. Scanlon, E. McDowell, and M. R. Hajj

Citation: Applied Physics Letters 103, 033903 (2013); doi: 10.1063/1.4816075

View online: http://dx.doi.org/10.1063/1.4816075

View Table of Contents: http://scitation.aip.org/content/aip/journal/apl/103/3?ver=pdfcov

Published by the AIP Publishing

AlP 


\title{
Performance enhancement of piezoelectric energy harvesters from wake galloping
}

\author{
A. Abdelkefi, ${ }^{\text {a) }}$ J. M. Scanlon, E. McDowell, and M. R. Hajj \\ Department of Engineering Science and Mechanics, MC 0219, Virginia Tech, Blacksburg, \\ Virginia 24061, USA
}

(Received 11 June 2013; accepted 1 July 2013; published online 16 July 2013)

\begin{abstract}
Experiments are performed to investigate the effects of wake galloping on the range of flow speeds over which a galloping-based piezoaeroelastic energy harvester can be effectively used. Two different upstream cylinders and a wide range of spacing between the upstream and downstream cylinders are considered. Bifurcation diagrams and type of instability for different setups are determined. The results show a complex relation between the upstream circular cylinder size, the spacing between the two cylinders, the flow speed, and the load resistance on one hand, and the level of harvested power on the other hand. C 2013 AIP Publishing LLC. [http://dx.doi.org/10.1063/1.4816075]
\end{abstract}

Due to arduous and expensive maintenance in the replacement of small batteries that have a finite life span, piezoelectric energy harvesting systems have received the most attention in the past few years as sustainable power sources that can be used in small volumes. Many investigations have focused on ambient vibration-based energy harvesting. ${ }^{1-6}$ On the other hand, harvesting energy from fluid flows at low speed is desirable in many applications including the deployment of self-powered sensors or batteries in buildings, rivers, and airstreams. Several recent studies $^{7-13}$ have focused on the conversion of aeroelastic vibrations in airfoil sections to electrical power. Energy harvesting from vortex-induced vibrations of circular cylinders has also been investigated in a few studies. ${ }^{14-16}$ Another aeroelastic phenomenon that has shown promise for harvesting energy is the galloping of prismatic structures. Transverse galloping of an elastic bluff body occurs when the wind speed exceeds a critical value and, consequently, the body starts to oscillate. ${ }^{17}$ Sirohi and Mahadik proposed harvesting energy from transverse galloping of a structure that has an equilateral triangle section tip mass. ${ }^{18}$ Abdelkefi et al. ${ }^{19-23}$ investigated the effects of the cross-section geometry, Reynolds number, electrical load resistance, and ambient temperature on the onset speed of galloping and the performance of piezoaeroelastic energy harvesters. Yang et $a l^{24}$ experimentally investigated the effects of the crosssection geometry on the performance of galloping-based piezoelectric energy harvesters in laminar flow conditions.

Another type of aeroelastic vibrations is the wake galloping where a cylinder placed in the wake of another cylinder exhibits cross-stream oscillations. The extent of wake galloping depends on the distance between the two cylinders. In this work, we consider a piezoaeroelastic energy harvester that is based on the wake galloping of a square section with the objective of extending energy harvesting to a broader range of flow speeds. The harvester is composed of a unimorph piezoelectric cantilever beam with a tip mass that consists of a square section, as shown in Fig. 1. The active length, width, and thickness of the aluminum alloy substrate

a)Electronic mail: abdes09@vt.edu. cantilever beam are $15.24 \mathrm{~cm}, 1.8 \mathrm{~cm}$, and $0.305 \mathrm{~mm}$, respectively. The dimensions of the square cylinder section are $26.67 \mathrm{~cm}$ (length) and $1.28 \mathrm{~cm}$ (width). Its weight is $7.6 \mathrm{~g}$. To harvest energy, we use a piezoelectric material (MFCM8514-P2, Smart Material Corp.) that is bonded by two in-plane electrodes of negligible thicknesses connected to an electrical load resistance. The natural frequency of this harvester is equal to $1.74 \mathrm{~Hz}$. An open-circuit wind tunnel with a $520 \mathrm{~mm} \times 515 \mathrm{~mm}$ test section is used to carry out the tests.

In the first set of experiments, we investigate the response of the harvester when placed on its own (without an upstream cylinder) in the wind tunnel. Initial displacements were applied to determine the onset speed of galloping of this harvester. Below a wind speed of $0.4 \mathrm{~m} / \mathrm{s}$, all disturbances were damped. Limit-cycle oscillations (LCOs) were observed at higher speeds. Consequently, it was determined

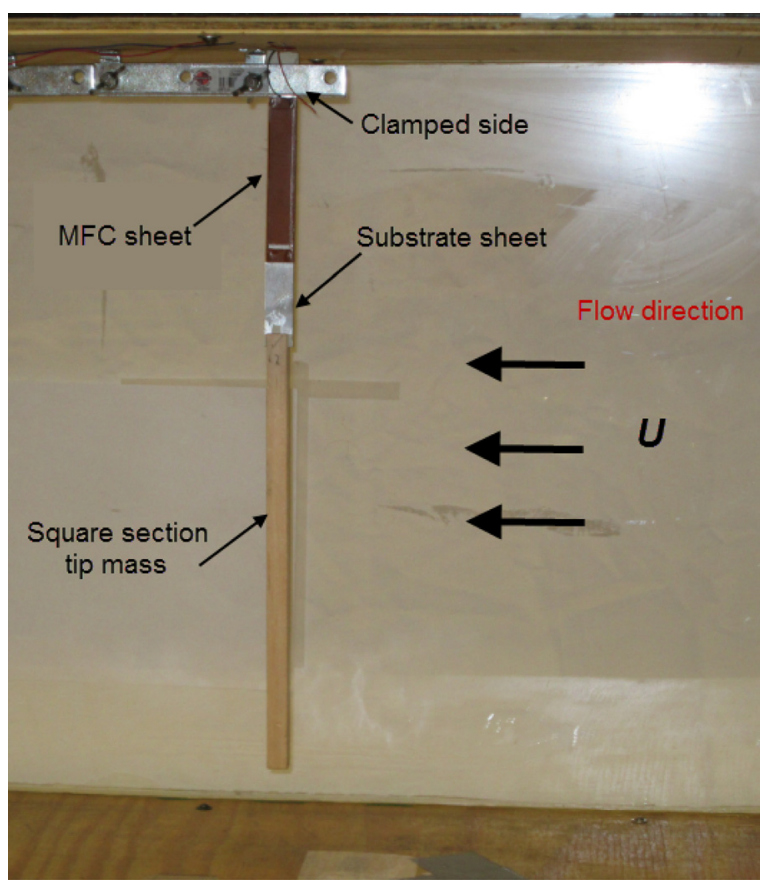

FIG. 1. Experimental setup showing a galloping-based piezoaeroelastic energy harvester in a wind tunnel. 
that the onset speed of galloping is $0.4 \mathrm{~m} / \mathrm{s}$. This speed is smaller than those reported in the literature (e.g., $2.5 \mathrm{~m} / \mathrm{s}$ in Yang et al., ${ }^{24} 8 \mathrm{mph}(3.57 \mathrm{~m} / \mathrm{s})$ in Sirohi and Mahdik, ${ }^{18}$ and $4 \mathrm{~m} / \mathrm{s}$ in $\mathrm{Kwon}^{25}$ ).

The plotted curves in Fig. 2 show variations of the average harvested power for different load resistances as the wind speed is increased from $0.3 \mathrm{~m} / \mathrm{s}$ to $1.7 \mathrm{~m} / \mathrm{s}$. The average harvested power is calculated as follows:

$$
P_{a v g}=\frac{V_{r m s}^{2}}{R},
$$

where $V_{r m s}$ is the root mean square (RMS) of the generated voltage and $R$ is the electrical load resistance.

Clearly, increasing the wind speed results in an increase in the average harvested power for all electrical load resistances. We also note that increasing the electrical load resistance yields an increase in the RMS generated voltage. However, the average harvested power is the highest for $R=10^{6} \Omega$. This is further illustrated in Fig. 3 that shows the variations of the average harvested power as a function of the electrical load resistance and for two different wind speeds. It follows from Fig. 3 that there is an optimum value of the electrical load resistance at which the average harvested power is maximum for both wind speeds. On the other hand, it is noted that, for higher values of the electrical load resistance $\left(R>10^{6} \Omega\right)$, the generated voltage stabilizes. We conclude that a galloping-based piezoaeroelastic energy harvester can be designed to generate energy at low wind speeds $(<1.7 \mathrm{~m} / \mathrm{s})$ and with a low cut-in speed of the order of $0.4 \mathrm{~m} / \mathrm{s}$. Furthermore, we observe that this harvester has a supercritical Hopf bifurcation. In fact, when we increased and decreased the wind speed values between $0.4 \mathrm{~m} / \mathrm{s}$ and $1.7 \mathrm{~m} / \mathrm{s}$, we got the same bifurcation diagram curves without hysteresis.

In the second set of experiments, we investigate the harvester's performance when subjected to wake galloping. For this, we place the same harvester in the wake of a circular cylinder as shown in Fig. 4. We consider two different upstream circular cylinders. The first has length, diameter, and weight that are, respectively, equal to $26.67 \mathrm{~cm}, 2.51 \mathrm{~cm}$,

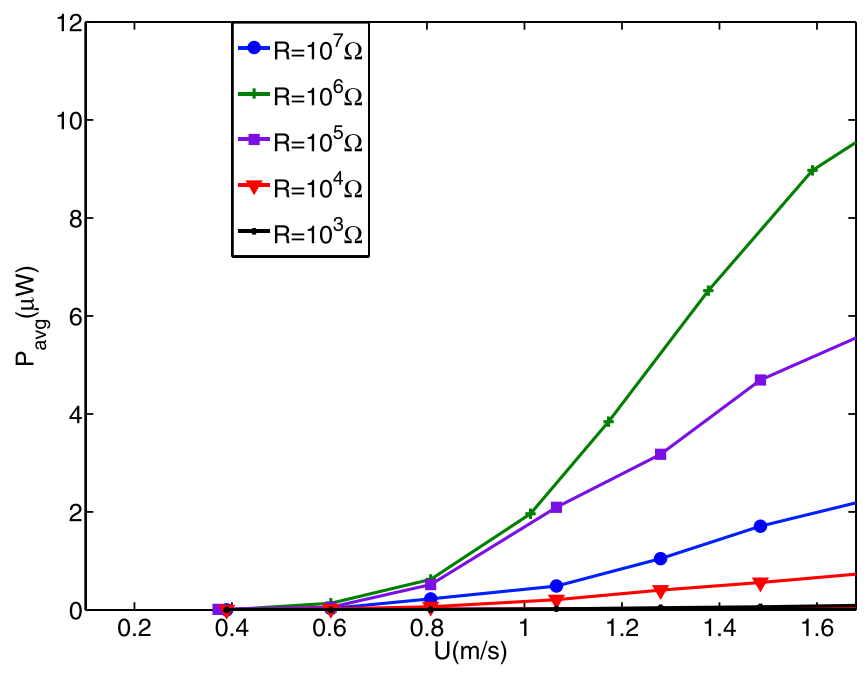

FIG. 2. Bifurcation diagrams of the average harvested power for different load resistances.

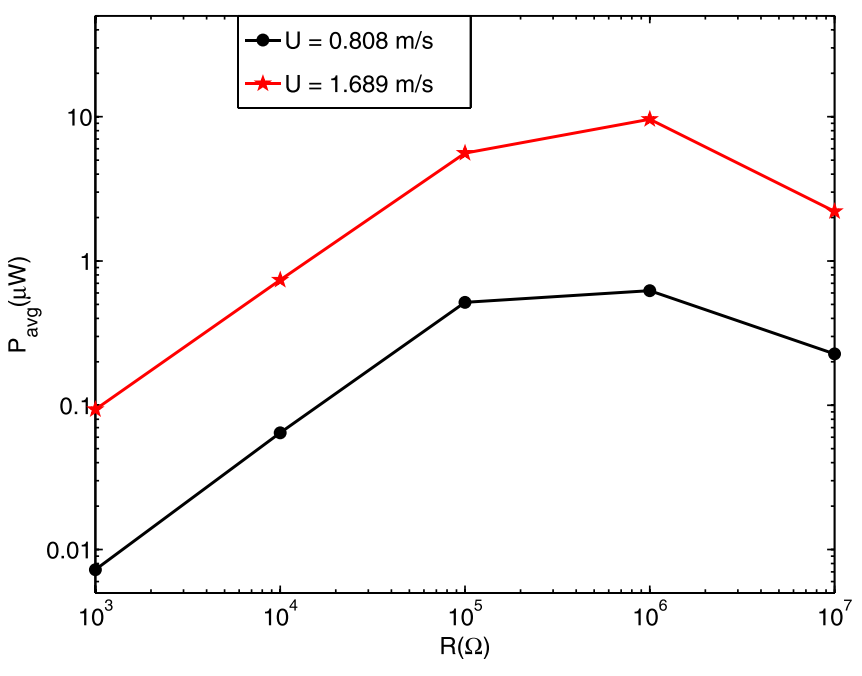

FIG. 3. Variations of the average harvested power as a function of the electrical load resistance for two different wind speeds.

and $56.8 \mathrm{~g}$. The dimensions and weight of the second cylinder are $27.15 \mathrm{~cm}$ (length), $1.25 \mathrm{~cm}$ (diameter), and $12.8 \mathrm{~g}$. We focused only on the variations of the RMS generated voltage when the electrical load resistance was set equal to $10^{7} \Omega$ to determine the effects of the spacing distance $(D)$ on the performance of the harvester. Placing the larger circular cylinder in front of the harvester and varying the spacing distance (D) from $4 \mathrm{~cm}$ to $30 \mathrm{~cm}$ and the wind speed from $0.4 \mathrm{~m} / \mathrm{s}$ to $3.9 \mathrm{~m} / \mathrm{s}$, neither of the two cylinders oscillated. We concluded that the wake effects of this large cylinder do not cause wake galloping of the downstream square section. Placing the smaller circular cylinder upstream of the harvester, we observed that there is a critical value for the spacing between the two cylinders at which the harvester begins to oscillate

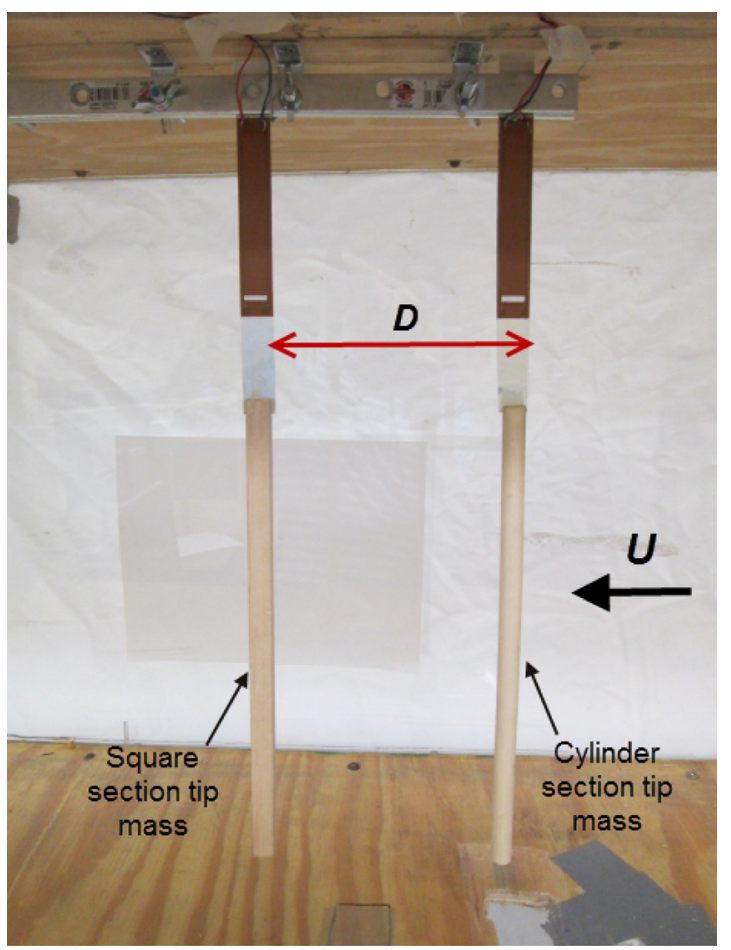

FIG. 4. Experimental setup of the circular and square section cylinders (wake effects). 


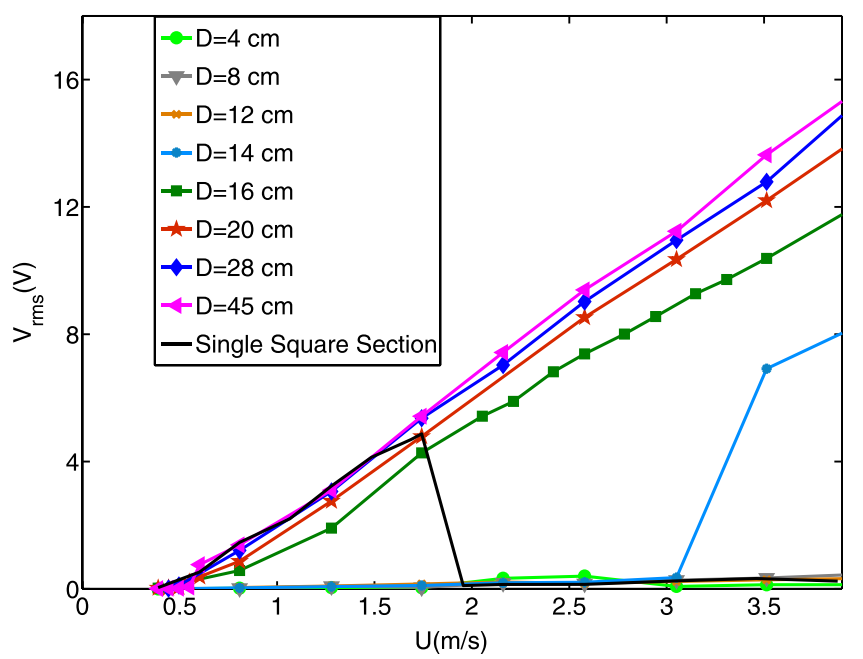

FIG. 5. Bifurcation diagrams of the RMS generated voltage for different spacing distances and when the electrical load resistance is equal to $10^{7} \Omega$.

and wake galloping takes place. The upstream cylinder does not oscillate over the operating range of wind speeds between $0.4 \mathrm{~m} / \mathrm{s}$ and $3.9 \mathrm{~m} / \mathrm{s}$. The plotted curves in Fig. 5 show the bifurcation diagrams of the RMS generated voltage for different spacing distances when increasing the wind speed and when the electrical load resistance is set equal to $10^{7} \Omega$. The plots show that the harvester does not oscillate over small spacing distances between $4 \mathrm{~cm}$ and $12 \mathrm{~cm}$. Without the upstream circular cylinder, the harvester stops oscillating near a wind speed of approximately $1.8 \mathrm{~m} / \mathrm{s}$. The plots show that $14 \mathrm{~cm}$ is the transition spacing distance at which the wake galloping is initiated and the harvester starts to generate power at speed larger than $3 \mathrm{~m} / \mathrm{s}$. For spacing values larger than $16 \mathrm{~cm}$, the harvester starts oscillating at $0.4 \mathrm{~m} / \mathrm{s}$. As the wind speed is increased, the harvester oscillates and has higher amplitudes and hence higher RMS generated voltage. We conclude that when the spacing distance $(D)$ is larger than $16 \mathrm{~cm}$, the wake effects of the upstream circular cylinder positively affect the response of the harvester for wind speeds larger than $1.8 \mathrm{~m} / \mathrm{s}$. Furthermore, the harvester has a supercritical Hopf bifurcation when the spacing distance $D$ is greater than $16 \mathrm{~cm}$.

To further investigate the observed sudden jump near $3 \mathrm{~m} / \mathrm{s}$ for the case of $D=14 \mathrm{~cm}$, we decreased the wind speed from $3.9 \mathrm{~m} / \mathrm{s}$ to $0.4 \mathrm{~m} / \mathrm{s}$, as shown in Fig. 6 . The results show that the harvester kept oscillating for wind speed values smaller than $3 \mathrm{~m} / \mathrm{s}$. The hysteresis in the range of wind speeds between $1.5 \mathrm{~m} / \mathrm{s}$ and $3 \mathrm{~m} / \mathrm{s}$ is a defining characteristic of a subcritical Hopf bifurcation. As such, the type of instability is dependent on the spacing distance.

To further understand the wake effects of the upstream circular cylinder on the performance of the harvester, we present in Fig. 7 the variations of the RMS generated voltage as a function of the spacing distance for different wind speeds, namely, $U=1.28 \mathrm{~m} / \mathrm{s}, 1.74 \mathrm{~m} / \mathrm{s}, 2.58 \mathrm{~m} / \mathrm{s}$, and $3.51 \mathrm{~m} / \mathrm{s}$ and when setting the electrical load resistance to $10^{7} \Omega$. Additionally, we show the voltage generated by the single galloping square section. The results show that at the low speeds $1.28 \mathrm{~m} / \mathrm{s}$ and $1.74 \mathrm{~m} / \mathrm{s}$ (cases when the single galloping square section is always oscillating), there is no significant improvement in the level of generated voltage when wake galloping is

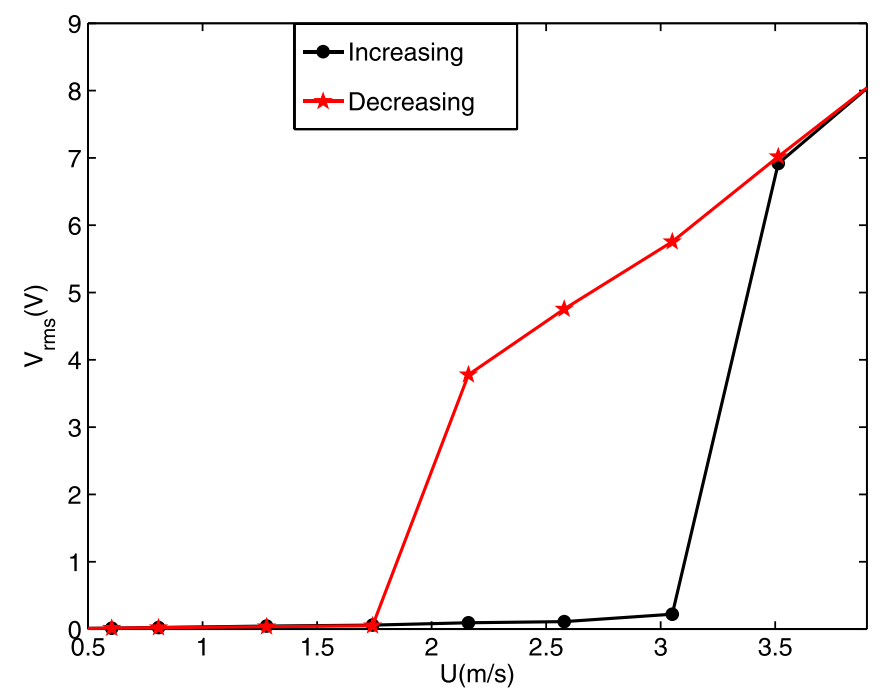

FIG. 6. Increasing/decreasing bifurcation diagrams of the RMS generated voltage when the spacing distance $D$ is equal to $14 \mathrm{~cm}$ and the electrical load resistance is equal to $10^{7} \Omega$.

introduced. When $U=1.28 \mathrm{~m} / \mathrm{s}$ and $U=1.74 \mathrm{~m} / \mathrm{s}$, the harvester can generate the same or slightly larger amount of energy for higher spacing distances than $24 \mathrm{~cm}$ and $20 \mathrm{~cm}$, respectively. On the other hand, there is a significant enhancement in the performance of the harvester at higher speeds $(2.58 \mathrm{~m} / \mathrm{s}$, and $3.51 \mathrm{~m} / \mathrm{s})$. At these wind speeds, the single square section cylinder does not generate power. However, high values of the generated voltage are obtained for both wind speeds due to wake galloping.

The plotted curves in Figs. 8 and 9 show the time histories of the generated voltage for the single galloping square section without an upstream circular cylinder and the wake galloping situation for a spacing distance of $35 \mathrm{~cm}$, wind speed of $1.28 \mathrm{~m} / \mathrm{s}$ (when both oscillate), and electrical load resistance of $10^{7} \Omega$. Clearly, adding an upstream circular cylinder does not affect the behavior of the square section cylinder at this speed. It is also noted that the time histories for both galloping and wake galloping situations are purely

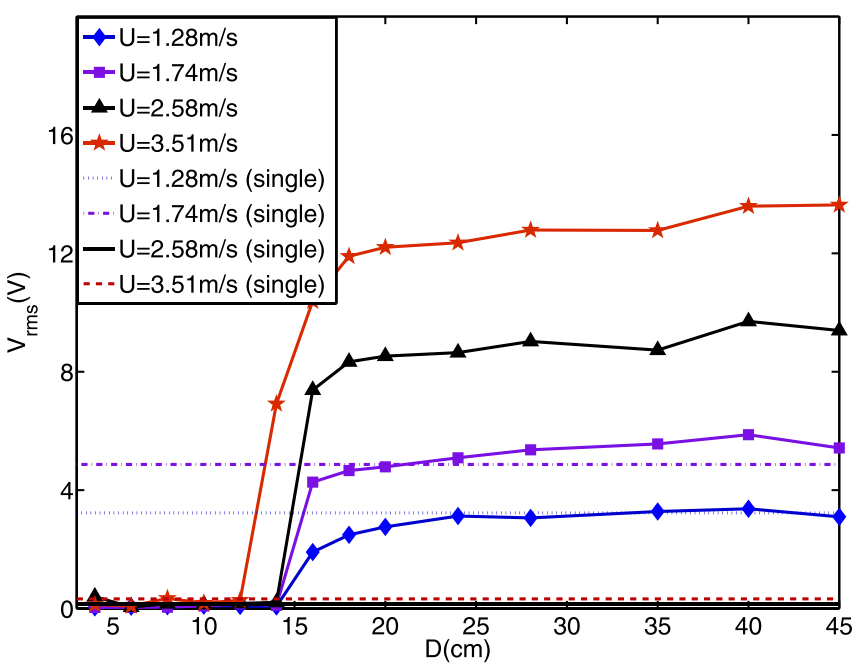

FIG. 7. Variations of the RMS generated voltage as a function of the spacing distance and comparison with the single square section in the wind tunnel for four different wind speeds and when the electrical load resistance is equal to $10^{7} \Omega$. 


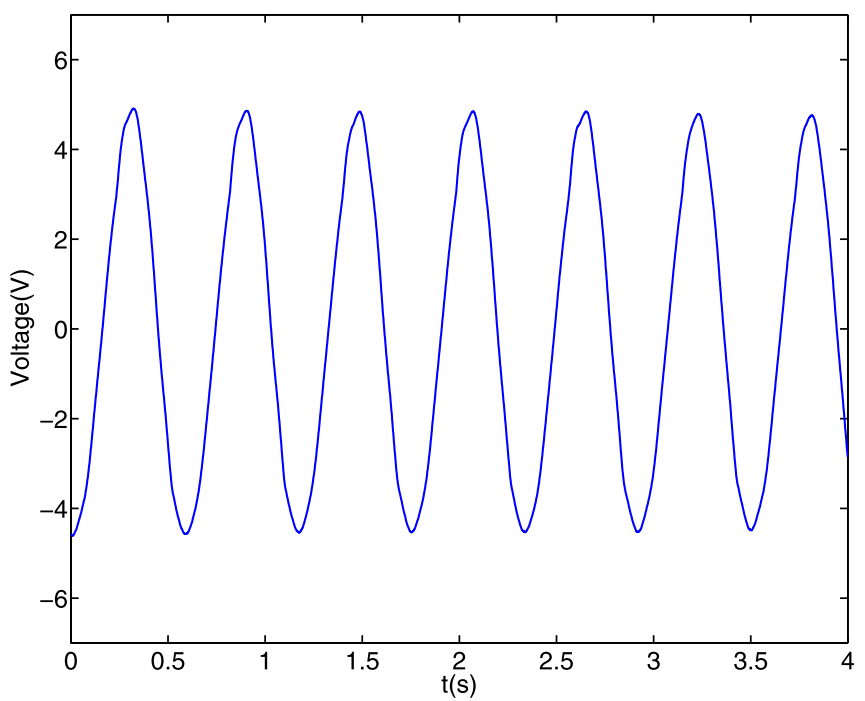

FIG. 8. Time history of the generated voltage for the galloping situation when $U=1.28 \mathrm{~m} / \mathrm{s}$ and $R=10^{7} \Omega$.

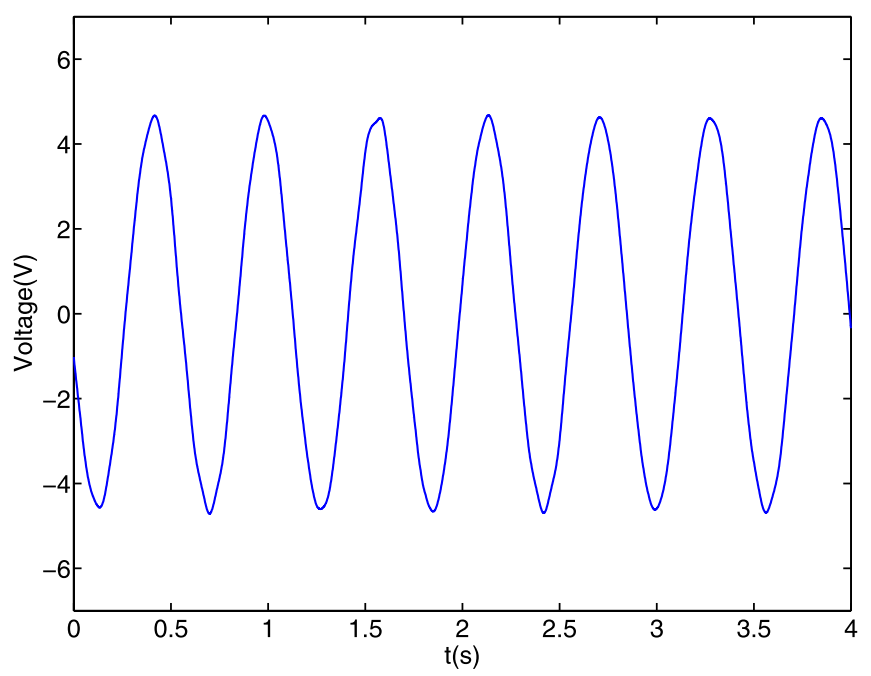

FIG. 9. Time history of the generated voltage for the wake galloping situation when $U=1.28 \mathrm{~m} / \mathrm{s}$ and $R=10^{7} \Omega$ and when the spacing distance is set equal to $35 \mathrm{~cm}$.

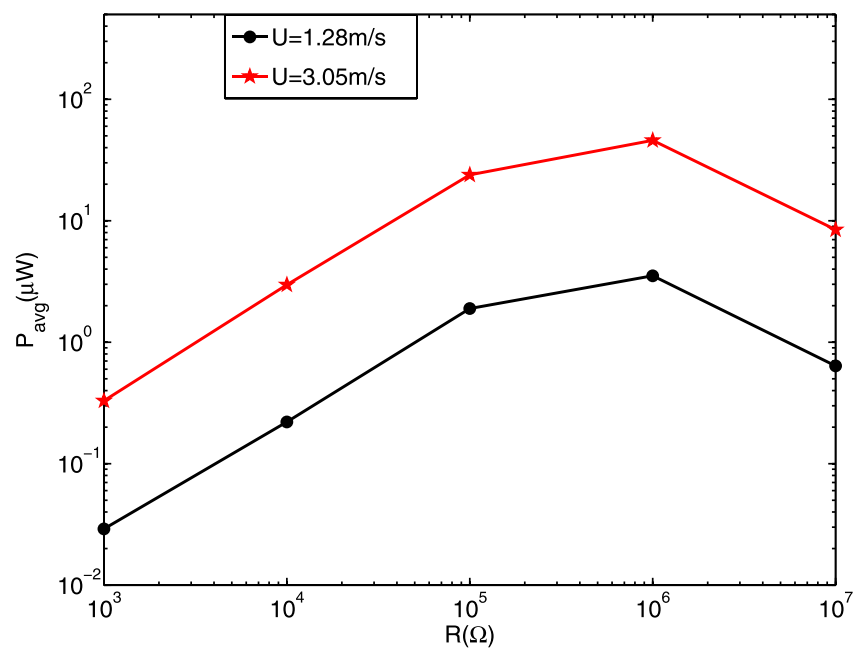

FIG. 10. Variations of the average harvested power as a function of the electrical load resistance for two different wind speeds when the spacing distance is set equal to $24 \mathrm{~cm}$. sinusoidal with a frequency almost equal to $1.74 \mathrm{~Hz}$, which is the natural frequency of the harvester.

To determine the effects of the load resistance on the performance of the harvester, we present in Fig. 10 the variation of the average harvested power as a function of the electrical load resistance for two different wind speeds, namely, $U=1.28 \mathrm{~m} / \mathrm{s}$ and $U=3.05 \mathrm{~m} / \mathrm{s}$ for a spacing distance $D$ of $24 \mathrm{~cm}$. Clearly, we note that there is a specific value of the electrical load resistance at which the average harvested power is maximized for both wind speeds. This optimum value of the electrical load resistance is near $10^{6} \Omega$. On the other hand, it is also noted that the variation of the RMS generated voltage is always the same when increasing the load resistance. In fact, for higher values of the electrical load resistance $\left(R>10^{6} \Omega\right)$, the generated voltage stabilizes.

In summary, we designed a square galloping energy harvester that can generate energy at low speeds $(<1.7 \mathrm{~m} / \mathrm{s})$ and with a cut-in speed equal to $0.4 \mathrm{~m} / \mathrm{s}$. Furthermore, we have shown that wake galloping can be used to enhance the performance of a galloping-based piezoaeroelastic energy harvester. Particularly, the range of speeds over which energy can be harvested can be significantly widened. It is to be noted, however, that the level of enhancement is dependent on the wake effects as determined by the size of the upstream circular cylinder and the spacing distance between the two cylinders. Of particular importance is the fact that the type of instability is dependent on the spacing distance between the two cylinders. It was also demonstrated that, depending on the placement of the harvester (urban areas, ventilation outlets, river, lifting components in aircraft structures), an enhanced piezoaeroelastic system can be designed with an appropriate selection of the diameter of the cylinder, the spacing distance between the square section and the circular cylinder, and the electrical load resistance.

${ }^{1}$ A. F. Arrieta, P. Hagedorn, A. Erturk, and D. J. Inman, Appl. Phys. Lett. 97, 104102 (2010).

${ }^{2}$ I. Kim, H. Jung, B. Lee, and S. Jang, Appl. Phys. Lett. 98, 214102 (2011).

${ }^{3}$ A. Abdelkefi, F. Najar, A. H. Nayfeh, and S. Ben Ayed, Smart. Mater. Struct. 20, 115007 (2011).

${ }^{4}$ A. Abdelkefi, A. H. Nayfeh, and M. R. Hajj, Nonlinear Dyn. 67, 1147-1160 (2012).

${ }^{5}$ A. Karami and D. J. Inman, Appl. Phys. Lett. 100, 042901 (2012).

${ }^{6}$ R. Masana and M. F. Daqaq, J. Appl. Phys. 111, 044501 (2012).

${ }^{7}$ M. Bryant and E. Garcia, Proc. SPIE 7288, 728812 (2009).

${ }^{8}$ A. Erturk, W. G. R. Vieira, C. De Marqui, and D. J. Inman, Appl. Phys. Lett. 96, 184103 (2010).

${ }^{9}$ A. Abdelkefi, A. H. Nayfeh, and M. R. Hajj, Nonlinear Dyn. 67, 925-939 (2012).

${ }^{10}$ A. Abdelkefi, A. H. Nayfeh, and M. R. Hajj, Nonlinear Dyn. 68, 519-530 (2012).

${ }^{11}$ A. Abdelkefi, A. H. Nayfeh, and M. R. Hajj, Nonlinear Dyn. 68, 531-541 (2012).

${ }^{12}$ V. C. Sousa, M de M. Anicezio, C. De Marqui, and A. Erturk, Smart Mater. Struct. 20, 094007 (2011).

${ }^{13}$ A. Abdelkefi, M. R. Hajj, and A. H. Nayfeh, J. Intell. Mater. Syst. Struct. 23, 1523-1531 (2012).

${ }^{14}$ H. D. Akaydin, N. Elvin, and Y. Andrepoulos, Smart. Mater. Struct. 21, 025007 (2012).

${ }^{15}$ A. Abdelkefi, M. R. Hajj, and A. H. Nayfeh, Nonlinear Dyn. 70, 1377-1388 (2012).

${ }^{16}$ A. Mehmood, A. Abdelkefi, M. R. Hajj, A. H. Nayfeh, I. Akhtar, and A. Nuhait, J. Sound Vib. 332, 4656-4667 (2013).

${ }^{17}$ J. P. Den Hartog, Mechanical Vibrations (McGraw-Hill, New York, 1956).

${ }^{18}$ J. Sirohi and R. Mahadik, J. Intell. Mater. Syst. Struct. 22, 2215-2228 (2011). 
${ }^{19}$ A. Abdelkefi, M. R. Hajj, and A. H. Nayfeh, Nonlinear Dyn. 70, 1355-1363 (2012).

${ }^{20}$ A. Abdelkefi, M. R. Hajj, and A. H. Nayfeh, Smart Mater. Struct. 22, 015014 (2013)

${ }^{21}$ A. Abdelkefi, Z. Yan, and M. R. Hajj, Smart Mater. Struct. 22, 025016 (2013).
${ }^{22}$ A. Abdelkefi, Z. Yan, and M. R. Hajj, Smart Mater. Struct. 22, 055026 (2013).

${ }^{23}$ A. Abdelkefi, Z. Yan, and M. R. Hajj, J. Intell. Mater. Syst. Struct. (2013).

${ }^{24}$ Y. Yang, L. Zhao, and L. Tang, Appl. Phys. Lett. 102, 064105 (2013).

${ }^{25}$ S. D. Kwon, Appl. Phys. Lett. 97, 164102 (2010). 